\title{
AÇÃO, FUNDAÇÃO E AUTORIDADE EM HANNAH ARENDT
}

Leonardo Avritzer

Na medida em que se completam 30 anos da morte de Hannah Arendt, duas questões se tornam cada vez mais claras: Hannah Arendt foi uma das principais filósofas e pensadoras sobre a natureza do político na segunda metade do século XX e a profusão de obras sobre o seu pensamento é cada vez maior (Cannovan, 1992; Villa, 1996; Benhabib, 1996; Calhoum, 1997; Villa, 2000); em segundo lugar, Hannah Arendt, nas suas principais obras, conseguiu não apenas resgatar uma dimensão da política relegada a um segundo plano absoluto na modernidade tardia como também mostrar a relevância dessa concepção para a política contemporânea. No entanto, à medida que novos trabalhos sobre a obra de Hannah Arendt se acumulam (Villa, 1996; Benhabib, 1996; Villa, 2000; Hammer, 2002), uma antinomia fica cada vez mais clara: de um lado, o resgate da dimensão da ação entre os atenienses não contentou à própria Arendt que, ao longo da sua obra, realizou um itinerário que a levou da Grécia à Roma e de Roma à nascente república americana; de outro lado, alguns trabalhos recentes mostram que a inspiração romano-republicana de Hannah Arendt é capaz de resgatar a idéia de fundação e autoridade apenas às custas dos ele- 
mentos mais igualitários do conceito de ação (Brunkhorst, 2000). Assim, se o problema da Hannah Arendt de A Condição Humana é que o resgate de um conceito de ação se perde na incapacidade de fundamentá-lo enquanto modelo de institucionalização do presente (Taminiaux, 2000: 171), já, no caso dos escritos sobre fundação e autoridade e do encontro de Hannah Arendt com o pensamento romano, fica a impressão de que a fundamentação do conceito de ação depende de um acesso diferenciado ao passado que fundamentaria a capacidade dos indivíduos de agir (Hammer, 2002: 136).

Há, assim, um problema não resolvido na obra de Hannah Arendt que poderia ser anunciado nos seguintes termos: se o ideal da ação ateniense é baseado em uma igualdade intrínseca entre os indivíduos, o ideal da fundação romana seria baseado em um pertencimento ao Senado e um acesso seletivo ao passado. Sendo assim, igualdade e hierarquia estariam em tensão nos dois momentos funda148 mentais da obra arendtiana. Esse artigo irá tentar reconstituir o itinerário que levou Arendt da Grécia a Roma e analisar a inter-relação entre os dois conceitos, ação e fundação. No primeiro caso, Hannah Arendt vai a Atenas para buscar, no conceito de ação utilizado pelos gregos, o fundamento de um conceito de política e de público. Nesse empreendimento, como é sabido, Arendt rompe não apenas com os modernos, mas também com a visão da política dos principais pensadores do mundo helênico, em particular Aristóteles e Platão (Villa, 1996). No segundo caso, Hannah Arendt vai a Roma para tentar resgatar, nas obras de Virgílio e Cícero, um conceito de autoridade que explique a facilidade da conquista do coração das massas modernas pelo totalitarismo e apontar a quebra nas sociedades modernas de uma dimensão intermediária de autoridade que permitiria ao Estado totalitário relacionar-se diretamente com as massas. Se a descrição do itinerário arendtiano não constitui nenhuma novidade (Taminiaux, 2000), o que iremos argumentar 
neste trabalho é que, longe de uma articulação coerente, esse itinerário apresenta uma tensão que a autora só é capaz de resolver, parcialmente, ao se mover novamente em direção à modernidade no seu livro Da Revolução.

Este artigo terá três partes. Cada uma delas irá dedicar-se à abordagem de um conceito central e irá relacioná-lo com um momento histórico resgatado por Hannah Arendt. Na primeira parte, trataremos da relação de Hannah Arendt com o pensamento ateniense e da diferenciação das três categorias centrais para o entendimento da modernidade: o labor, a obra e a ação. Iremos discutir o que funda a ação como artificialidade e a relação que Hannah Arendt estabelece, em A Condição Humana, entre a artificialidade da ação e a ausência de institucionalização. Apontaremos os motivos (corretos, a nosso ver) que deixam Hannah Arendt ao final de A Condição Huma$n a$ insatisfeita com a forma pela qual os atenienses negavam a necessidade de institucionalização da ação.

Na segunda parte deste artigo, iremos mostrar a trajetória especificamente romana do pensamento arendtiano. Utilizaremos, como base para a recuperação de um momento romano no pensamento de Hannah Arendt, os ensaios sobre a autoridade e a liberdade e partes selecionadas do seu livro póstumo e incompleto A Vida do Espírito (The Life of the Mind). Examinaremos o elemento mais classicamente republicano da obra arendtiana, o conceito de fundação e a sua vinculação com a recuperação do conceito de autoridade. Ambos colocam o problema da vinculação da ação com um momento histórico constitutivo e expressam um entendimento do exercício da política como um "aumentar" desse momento que seria a base do conceito arendtiano de autoridade. Iremos atribuir a tentativa arendtiana de ir a Roma, à busca de uma forma de institucionalização para o conceito de ação resgatado de Atenas. Roma, diferentemente de Atenas, conhecia o contrato e, assim, entendia o direito como vinculando o futuro. É essa noção, sem a qual a idéia de institucionalização 
é impossível, que leva Hannah Arendt a Roma. No entanto, a integração do pensamento romano cria uma tensão com o resgate da ação em Hannah Arendt. Essa tensão é provocada pelo fato de que a pluralidade do humano e a publicidade da ação não fazem parte de uma tradição cujo conceito de fundação remete a um grupo particular, os patrícios e seus privilégios de ocupação do poder. Aí reside a tensão inelutável entre Atenas e Roma, entre ação, fundação e autoridade da qual, a nosso ver, o pensamento arendtiano nunca conseguiu plenamente escapar.

Há ainda um terceiro momento no pensamento arendtiano que é representado pelo encontro com a experiência republicana norte-americana. O movimento de Arendt em busca de um terceiro momento histórico parece ter duas justificativas: a procura de um caso que pudesse explicar o princípio da natalidade e da refundação. Os Estados Unidos seriam o caso ideal capaz de concretizar o princípio

150 da natalidade expresso pelo não dos puritanos à sociedade inglesa e sua determinação de construir uma nova ordem política. Mas há também, a nosso ver, um segundo elemento na sociedade americana que a tornou atrativa para o pensamento arendtiano. $\mathrm{O}$ fato de os Estados Unidos, diferentemente de Roma, constituírem um caso horizontal e, portanto, democrático de fundação expresso no constitucionalismo. O nosso argumento, neste artigo, será o de que, de todas as tentativas arendtianas, apenas o caso americano expressaria, simultaneamente, um elemento de participação horizontal e de fundação republicana. Essa, na nossa opinião, deve ser a tonalidade da reapropriação arendtiana da política.

\section{Antigüidade política e crítica da modernidade}

Os motivos que levaram Hannah Arendt a um reexame da política no mundo antigo são os mais modernos possíveis: de um lado, a crítica à predominância do conceito de fabri- 
cação no mundo moderno surge de uma crítica vigorosa ao pensamento marxiano ${ }^{1}$, Hannah Arendt, em A Condição Humana $^{2}$, estabelece uma diferença entre a naturalidade e a artificialidade justamente para apresentar uma alternativa ao pensamento marxiano. Há um segundo motivo absolutamente moderno que conduz Hannah Arendt ao mundo antigo: a individualização do conceito de liberdade. A liberdade no mundo antigo é uma categoria coletiva e implica a existência de um projeto comum. Em Entre o Passado e o Futuro e, especialmente, no seu artigo "A Liberdade", Hannah Arendt irá buscar um conceito de liberdade alternativo ao do liberalismo para refundar o conceito de liberdade. Nesse sentido, tanto A Condição Humana quanto Entre o Passado e o Futuro são obras cuja incursão pelo mundo antigo tem uma fundamentação eminentemente moderna.

Hannah Arendt em A Condição Humana irá lançar as bases da reconstrução de um conceito de política através da diferenciação entre labor, obra e ação. A distinção entre labor, obra e ação tem como pano de fundo a procura de um conceito de política capaz de separar a naturalidade da artificialidade. Labor e obra estão no campo das atividades através das quais os homens ou renovam o ciclo natural da sua própria vida ou transformam os objetos naturais. Portanto, dentro da tradição marxiana seriam as atividades capazes de

1. Tanto o pensamento de Marx quanto o marxismo estão baseados em uma identidade entre o ato de transformação da natureza e o processo reflexivo. Para essa corrente, apenas a transformação da natureza pode ser considerada um ato reflexivo gerador de consciência. Nesse sentido, Marx seria o fundador do paradigma da produção e o defensor maior da identidade entre artificialidade e política. (Vide Marx, 1976; Habermas, 1968; Avritzer, 1996.)

2. Apesar de alguns autores, em especial Margareth Canovan, considerar As origens do totalitarismo como a obra principal de Hannah Arendt, parece-nos evidente que a construção do seu sistema filosófico começa com A Condição Humana. Neste artigo, iremos considerar a preocupação com o totalitarismo o elemento fundante $\mathrm{e}$ durador da obra de Hannah Arendt, mas iremos assumir que é a partir de A Condição Humana que essa preocupação encontra uma formulação filosófica. 
gerar reflexão. Hannah Arendt irá buscar na Grécia, em particular na Atenas pré-socrática, uma concepção alternativa. Ela a encontra na busca ateniense pela imortalidade e pela permanência identificada com as atividades eminentemente políticas. Nesse sentido, o que diferenciaria o labor e o trabalho, de um lado, e ação, do outro, seria a capacidade da ação de criar permanência: “ a imortalidade significa a permanência no tempo, a vida imortal nessa terra que foi dada, de acordo com os gregos, para a natureza e para os Deuses Olímpicos. Foi em contraste com esse pano de fundo de uma vida natural sempre renovável e de deuses imortais e eternamente jovens que estavam os homens - os únicos mortais em um universo imortal mas não eterno [...] Se acreditamos em Heródoto a diferença entre os dois [níveis] era fundamental para o auto-entendimento grego e anterior à articulação conceitual dos filósofos" (Arendt, 1958: 18).

Essa distinção será o ponto de partida para a separação 152 entre o labor, o trabalho e a ação e permitirá diferenciar as atividades humanas de acordo com a sua relação ou não com a natureza. $\mathrm{O}$ labor seria a atividade menos valorizada pelos gregos justamente pela sua fungibilidade absoluta. Ele envolveria as atividades de renovação do ciclo biológico do corpo humano e, portanto, incapazes de adquirir qualquer permanência. Sua principal característica é o consumo para manutenção do ciclo vital dos indivíduos. São as atividades ligadas à obra que, para Hannah Arendt, implicam a fabricação, e a questão aí seria pensar que tipo de permanência essas atividades produzem. Para a autora de A Condição Humana, a obra produz objetos cuja durabilidade depende da ação humana. A cadeira sem uso volta a ser um pedaço de madeira. No entanto, é a sua característica de durabilidade que irá interessar a Arendt. Para ela, “[...] é a durabilidade que fornece às coisas do mundo uma relativa independência dos homens que as produziram e as utilizam e que fornece a sua 'objetividade' [...]" (Arendt, 1958: 137). É possível notar nes- 
sa formulação um diálogo indireto com Marx, diálogo esse que se dissocia da idéia de uma objetividade a ser reapropriada pelos homens tal como o pensamento de Marx supõe (Colletti, 1985). Para Arendt, a durabilidade adquirida pela fabricação humana não é o problema. O problema, pelo contrário, é que a artificialidade produzida pela obra é limitada e deve ser colocada em contraste com a artificialidade que deriva das atividades puramente humanas. Esse é o itinerário que conduz ao contraste entre a obra e a ação.

O conceito de ação em Hannah Arendt é um dos elementos mais originais de sua obra. Ele se situa na interseção entre a igualdade e a diferença. Para a autora de $A$ Condição Humana, se os homens (e as mulheres) não fossem iguais, nós não seríamos capazes de entender uns aos outros; se não fossemos diferentes, não teríamos a necessidade de utilizar a linguagem para entendermos uns aos outros. Assim, a ação é a atividade puramente artificial entre os indivíduo que tem como precondição a igualdade e a pluralidade. Esse conceito, que poderia ser relacionado ao de diversos outros pensadores do século XX, separa-se de todos eles por sua ruptura radical com a assim chamada dialética do reconhecimento ${ }^{3}$, que é substituída por uma hierarquia de lugares nos quais a pluralidade poderá se expressar. Hannah Arendt rompe com uma dialética do reconhecimento própria ao pensamento de Hegel e Marx, de acordo com a qual, em todas as atividades humanas poderia haver um reconhecimento do outro enquanto igual, reconhecimento esse que estaria na base da cidadania (Brunkhorst, 2000). Para ela, o ato de reconhecimento do outro enquanto igual está ligado apenas às ativida-

3. A maior parte dos conceitos de cidadania elaborados a partir do século XIX irá justificar a cidadania por uma dialética do reconhecimento capaz de gerar um princípio intrínseco de igualdade. Essa chave para o entendimento da modernidade foi aberta por Hegel em sua Fenomenologia do espírito. A distinção arendtiana das atividades humanas rompe com ela. (Vide Brunkhorst, 2000.) 
des puramente humanas e, portanto, não poderia fazer parte das atividades da fabricação e do labor. Aí irá residir a base do seu conceito de espaço público. Uma das precursoras da recuperação do conceito de espaço público na modernidade tardia, Arendt supõe que a ação só poderia se desenrolar nesse espaço. O modelo para o conceito arendtiano de ação é a pólis ateniense com a sua diferenciação radical entre a oikia e o público. A oikia, a esfera privada, é o lugar da tirania, da hierarquia, do domínio de indivíduos uns pelos outros. Nesse sentido, há uma desigualdade inerente à oikia motivada não pelas relações humanas e sim pela mediação exercida pela natureza que implica necessariamente violência ${ }^{4}$. Ao mesmo tempo, o público arendtiano é mais radicalmente igualitário do que o espaço político nas formulações dos autores da dialética do reconhecimento. A igualdade e a pluralidade são constitutivas da noção arendtiana de público (Canovan, 1992) através da qual as atividades puramente humanas ocor154 rem no interior de um espaço constituído em comum pelos indivíduos. É nesse espaço que a política tem lugar e é com a recuperação desse espaço, tão claramente identificado pelos gregos, que Hannah Arendt vincula a sua obra.

Duas questões emergem quando pensamos na identificação arendtiana entre a política e a ação no mundo ateniense. A primeira delas é que, se é inegável o sucesso relativo do empreendimento arendtiano de recuperação de um conceito puramente humano e plural de política, por outro lado, não está claro que, para a própria Hannah Arendt, esse conceito de política seja suficiente. Para Arendt, há uma tensão entre a capacidade grega para a ação e sua incapacidade de pensar as formas de institucionalização dessa mesma ação. Arendt irá tentar em A Condição Humana identificar a forma de ação polí4. Essa concepção está também presente na Dialética do esclarecimento e em boa par-
te da teoria crítica. Sua origem é provavelmente a obra de Heidegger. 
tica por ela defendida com a política dos conselhos operários. No entanto, ela rapidamente percebeu que faltava à tradição grega um elemento de inserção da ação em uma perspectiva de futuro. Esse é o motivo que leva Arendt a Roma, onde ela irá identificar o contrato e a refundação como os elementos centrais para a renovação do conceito de ação.

\section{Da Grécia a Roma: contrato e refundação}

Diversos autores já observaram a preferência arendtiana pela tradição política grega quando comparada à romana. Margareth Canovan em seu livro Hannah Arendt cita a seguinte afirmação da autora: "eu gosto da antigüidade grega, mas nunca gostei da antigüidade romana" (Canovan, 1992: 143). Essa colocação, que inspirou um conjunto de colocações semelhantes sobre a preferência arendtiana em relação a Atenas quando comparada com Roma (Villa, 1996), não é, no entanto, completamente coerente com o sentido da obra arendtiana (Hammer, 2000: 125). Em A Condição Humana há mesmo uma passagem na qual Arendt compara a tradição política grega e a romana em outros termos: "Ainda que seja verdade que Platão e Aristóteles elevaram o processo deliberativo (lawmaking) e a construção da cidade ao nível mais elevado possível na vida política, isso não significa que eles foram capazes de alargar a experiência grega da ação e da política para que essa passasse a abranger o que mais tarde ficou conhecido como a genialidade política de Roma: legislação e fundação.” (Arendt, 1958: 195). A citação acima, que não é uma citação isolada na obra arendtiana e que perpassa outras obras, especialmente A Vida do Espírito, suscita duas questões que procuraremos responder nessa seção deste artigo. A primeira delas é o que, em A Condição Humana e na estrutura do pensamento arendtiano, coloca a necessidade de um detour a Roma? Em segundo lugar, quais são os elementos gregos e os elementos romanos no pensamento arendtiano e como 
entender a relação entre eles? Procuraremos responder nos parágrafos seguintes a ambas as questões.

O problema que levou Hannah Arendt a Roma é a incapacidade dos gregos de pensarem a institucionalização da ação e da política. Dois elementos estão na raiz dessa incapacidade: a baixa relevância atribuída pelos gregos à atividade legislativa (Taminiaux, 2000) e a inexistência de uma concepção de futuro entre os gregos. Hannah Arendt, como mostramos na seção anterior desse artigo, resgata entre os gregos uma concepção de política ligada à pura artificialidade das ações humanas e à pluralidade humana. Esse conceito desempenha no seu pensamento o papel de reverso da idéia moderna de política como parte da interação homemnatureza. Os gregos, na esfera pública, estabeleciam relações puramente humanas entre si baseada na igualdade e no uso da palavra. Se essa concepção é atrativa para Arendt, ela apresenta um problema que a autora procura sanar: como insti156 tucionalizar na política esse tipo de ação, entendendo por institucionalização um resultado capaz de sobreviver aos seus atores e ser renovado por outras gerações. Hannah Arendt oferece em A Condição Humana duas respostas a essa questão. A primeira delas é negar a necessidade da institucionalização. No entanto, essa resposta é claramente insuficiente, como diversos autores já notaram (Heller, 2000), porque a negação da institucionalidade é incapaz de gerar qualquer padrão de repetição continuada da ação. Daí surge a necessidade de analisar a segunda resposta arendtiana, aquela que a conduz a Roma.

O pensamento romano entendia o problema da institucionalização da ação de forma diferente do pensamento grego. Em primeiro lugar, porque, para os romanos, a atividade legislativa e legal tinha um peso maior na vida política expressa pela idéia da inviolabilidade dos contratos (pacta sunt servanda) (Taminiaux, 2000: 171). Arendt reconhece a pouca relevância que os gregos atribuíam às atividades legislativas e 
pensa o modelo romano como a forma de oferecer continuidade para a ação, isto é, aquilo que mantém unidos aqueles que interagem. No entanto, apesar de fazer uso da figura do contrato para pensar o elemento de continuidade da ação, Hannah Arendt não é strictu sensu uma contratualista. Ela não o é porque recorre mais à própria tradição religiosa, especialmente à idéia da promessa encontrada no Velho Testamento para pensar o problema da continuidade da ação. Para Arendt, a estabilização inerente à idéia de fazer promessas pode ser traçada tanto ao pensamento romano quanto a Abraão, que mostrou a capacidade dos pactos de gerarem padrões de ação (Arendt, 1958: 243). Assim, temos em Arendt duas tradições diferenciadas para pensar a maneira através da qual a continuidade da ação deve ser postulada. Ambas nos remetem para além do pensamento grego que, devido à ausência de uma idéia de futuro, não consegue tornar a ação mais do que um elemento exemplar do passado e do presente.

Esse elemento de continuidade da ação irá se juntar a um outro da tradição romana que é o da fundação. Para Hannah Arendt, Roma, diferentemente da Grécia, teve um momento de ação como fundação que foi a da criação de Roma como cidade eterna. Construída na base de acordos e promessas mútuos, a fundação de Roma era para Hannah Arendt não apenas um exemplo da exaltação de um espírito público, mas também uma forma de exaltação da tradição (Canovan, 1992: 143). No entanto, o momento de fundação para os romanos tem mais elementos do que os destacados por Arendt. A fundação constitui um ato de identidade e de grandeza a ser preservado indefinidamente através de sucessivas tentativas de renovação (Matthes, 2000: 40). Nesse sentido, o historiador - Lívio, por exemplo - não apenas conta a história, mas revela as características que a tornam susceptível de ser renovada. Desse modo, a fundação e a refundação romana remetem ao passado ainda mais que a visão cíclica de história dos gregos. 
Não é difícil perceber que a forma como Hannah Arendt funda o problema da institucionalização na sua teoria política é altamente problemática e está em tensão com o seu conceito de ação. De um lado, o conceito de fundação e de refundação introduz na obra arendtiana um componente mais ligado ao problema da reabilitação da tradição no mundo moderno do que à dimensão da renovação da ação. A tradição romana que Hannah Arendt procura resgatar, ainda que parcialmente em Entre o Passado e o Futuro, parece responder melhor ao problema da crise da autoridade do que ao problema da institucionalização da ação. Arendt identifica a autoridade com uma forma hierárquica de relação entre os indivíduos: "A relação de autoridade entre o que manda e o que obedece não se assenta nem na razão comum nem no poder que manda; o que eles possuem em comum é a própria hierarquia, cujo direito e legitimidade ambos reconhecem e na qual ambos têm lugar estável predeterminado" (Arendt, 1972: 129). É pos158 sível notar que a preocupação arendtiana com a autoridade desperta um elemento diferente na sua teoria da política do que a sua preocupação com a recuperação da ação entre os antigos. O que leva Arendt em busca de uma recuperação do conceito romano de autoridade, e é importante ressaltar que a autoridade não poderia ser um conceito grego (Villa, 1996: 159), não é a tentativa de dar uma solução para o problema da institucionalização da ação, um dos problemas arendtianos por excelência, e sim a tentativa de explicar a disponibilidade das massas, o outro problema arendtiano ${ }^{5}$. Assim, a primeira

\footnotetext{
5. Muitos dos intérpretes de Hannah Arendt consideram a sua preocupação com o autoritarismo o leitmotiv da sua obra. Para eles, Hannah Arendt buscou em sua obra fundamentalmente oferecer uma resposta para o fenômeno. Para Canovan, parece mais lógico dividir a obra arendtiana em duas fases: uma primeira, na qual a explicação do autoritarismo constitui o motivo fundamental, e um posterior, na qual a adaptação aos Estados Unidos gera a idéia de ação, do novo começo e da recuperação dos motivos republicanos. (Vide Canovan, 1992.) Essa versão parece mais próxima do entendimento de Young-Bruhel.
} 
questão importante a ser apontada em relação ao detour romano de Hannah Arendt é que ele não a ajuda a solucionar o problema que leva Hannah Arendt da Grécia a Roma, qual seja, o problema da institucionalização de uma forma de ação que é um fim em si mesma.

Vale a pena analisar uma segunda dimensão do encontro entre o pensamento arendtiano e a prática política romana, que é o funcionamento das instituições políticas romanas. Se, por um lado, elas propiciavam o desenrolar da política em um mundo construído em comum pelos homens livres, por outro, propiciavam algo que, de forma alguma, agradava a Hannah Arendt: a transformação do espaço público no lugar da turba e da manipulação política. A passagem da Grécia para Roma entre A Condição Humana e a redação do Da Revolução cujo centro histórico é preenchido pela experiência romana e norte-americana evidencia a necessidade de dar às instituições um papel maior na ação pública. Os romanos solucionavam o problema da manipulação da plebe através da distinção entre a autoridade do Senado e o poder do Povo (Brunkhorst, 2000: 187). Nesse sentido, a institucionalização poderia aparecer como uma solução, só que o seu preço seria a substituição da igualdade pela hierarquia.

Assim, parece bastante claro que não há uma complementaridade entre o itinerário grego e o itinerário romano da obra de Hannah Arendt, mas sim uma tensão. Isso é provocado pelo fato de os dois elementos inspiradores da obra de Arendt estarem em tensão: a tentativa de recuperar a autoridade como resposta ao problema do totalitarismo, que alguns intérpretes de Arendt consideram a inspiração fundamental da sua obra (Canovan, 1992), com a tentativa de reconstrução do conceito de ação ao qual outros intérpretes atribuem centralidade (Villa, 1996). Essa tensão pode ser expressa nos seguintes termos: o conceito de "[...] autoridade parece estar em conflito com a convicção bási- 
ca arendtiana sobre o que é uma política verdadeiramente autêntica" (Villa, 1996: 158). Nesse sentido, o itinerário romano de Arendt não lhe permite oferecer uma saída para como institucionalizar o conceito de ação por ela resgatado. Duas respostas possíveis se colocam para o problema: a primeira é, como propõe Dana Villa, considerar que o objetivo arendtiano é mostrar que a época de vigência do conceito de autoridade foi do momento romano ao Iluminismo e assim indicar o que seria um conceito pós-autoritário da política. Essa concepção, ainda que atraente, não parece corresponder plenamente aos objetivos da autora de Entre o Passado e o Futuro. A segunda possibilidade é procurar mostrar, com Hannah Arendt e contra Hannah Arendt, que a articulação histórica possível entre ação e fundação se dá na própria modernidade. Essa articulação pode ser feita através do conceito de natalidade, isto é, do novo começo. Na última seção desse artigo, iremos defender tal posição a 160 partir de uma apropriação seletiva da obra Da Revolução.

\section{Natalidade e novo começo político}

O conceito de natalidade ocupa um lugar seminal na obra arendtiana, estando presente em todos os seus trabalhos e ocupando cada vez mais o centro de cada um deles. O seu significado é o da indeterminação da ação desencadeada por um novo nascimento e, conseqüentemente, pela possibilidade sempre aberta de instaurar-se um novo começo na política (Bowen-Moore, 1989: 22). Já na parte final da Origem do Totalitarismo, a autora nos diz que o começo é a capacidade suprema do indivíduo e que, politicamente, ele equivale à liberdade humana (Arendt, 1951: 479).

Mas será em A Condição Humana, em Da Revolução e em A Vida do Espírito que o conceito de natalidade será articulado tanto na sua dimensão privada quanto na sua dimensão pública. O conceito de natalidade, na sua dimensão privada, expressa o fato de que cada novo nascimento define a 
condição humana enquanto única. Na medida em que cada novo nascimento é único, ele é também um novo começo. Essa dimensão agostiniana ${ }^{6}$ do pensamento de Hannah Arendt expressa a idéia de indeterminação da trajetória humana no domínio privado. Mas é no campo do público que o conceito de natalidade adquire sua dimensão plena. Seu principal objetivo dentro da estrutura da obra política de Hannah Arendt é negar a idéia de irreversibilidade da ação. Toda ação seria irreversível e o sentido das diferentes ações imutável se não fosse possível descongelar uma ação já concluída. O conceito de natalidade irá desempenhar esse papel ao permitir um novo começo. Ele também irá associar ação e biografia, na medida em que uma das suas características é retirar da ação a sua anonimidade.

Hannah Arendt identificou a idéia de natalidade em Origens do Totalitarismo e em A Condição Humana com um episódio político específico, a revolução húngara de $1956^{7}$. Na sua análise sobre os episódios de 1956, Hannah Arendt defende a natalidade contra a institucionalização. Para ela, a grandeza do evento não poderia ficar limitada aos seus doze dias de duração. Pelo contrário, ele deveria ser avaliado pela grandeza e pela tragédia que desencadeou. O elemento central da análise arendtiana sobre a Hungria é a maneira pela qual o agir coletivo se destaca do continuum da história. Um conjunto de estudantes realiza uma manifestação e, no dia seguinte, vai até a radio de Budapeste pedir a divulgação de um manifesto de 16 pontos. A polícia política presente no prédio tenta dispersá-los, mas há uma

6. Em seu livro A Cidade de Deus, Santo Agostinho coloca a questão do novo começo ao afirmar que o homem tem não apenas a capacidade para realizar o novo começo, mas que ele próprio é o novo começo. (Vide Bowen-Moore, 1989: 24.)

7. O texto de Hannah Arendt sobre a Revolução Húngara acabou sendo publicado como um posfácio a uma das edições de Origens do totalitarismo publicado pela Georg Allen and Unwin em 1966. 
reação de uma massa indistinta de indivíduos que, ao ser atacada pela polícia política, reage e toma as suas armas. Os trabalhadores nas fábricas ficam sabendo do episódio e se juntam a essa massa de indivíduos. O exército, ao ser chamado, nega-se a intervir e, com isso, a revolução está em movimento. Para Hannah Arendt, “[...] não foram os programas ou o manifesto que jogaram qualquer papel. O que desencadeou a revolução foi o puro momento do agir em comum da população como um todo cuja demanda era tão óbvia que dispensa uma formulação mais específica” (Arendt, 1966: 496). Ou seja, o elemento central do que Arendt identifica como ação durante a Revolução Húngara é o agir em concerto, por um certo momento. O fato de que todos os episódios duraram doze dias é para ela absolutamente irrelevante diante do fato, de importância superior, que é a demonstração pública de que o autoritarismo pode ser derrotado pela ação concertada da população.

162 Há um segundo elemento de importância seminal de suas reflexões sobre a Hungria que é a valorização positiva do papel dos conselhos. Hannah Arendt resgata uma discussão que pertence à tradição marxiana, mas com uma interpretação radicalmente distinta. Para ela, "os conselhos operários são a mesma organização, com mais de cem anos de vida, que surgiu sempre que se permitiu ao povo por alguns dias, por algumas semanas, ou meses desempenhar as suas atividades políticas, sem um governo (ou programa partidário) imposto por cima" (Arendt, 1966: 497). A colocação arendtiana difere da marxiana em um aspecto mais evidente que é a negação de qualquer elemento partidário no entendimento dos conselhos (Sitton, 1992). Mas ela difere da interpretação marxiana em um segundo aspecto ainda mais relevante: para Arendt os conselhos não eram conselhos operários e sim conselhos revolucionários ou de bairro. Na sua análise sobre os conselhos húngaros, ela diferenciou os conselhos revolucionários dos conselhos de 
trabalhadores. A sua atenção esteve voltada para as funções políticas dos primeiros. Para ela, os conselhos revolucionários eram uma resposta à tirania política e, ao mesmo tempo, uma alternativa a um sistema representativo baseado em facções: "[...] assim se a origem histórica do sistema de partidos se assenta no parlamento e nas suas facções, [por outro lado] os conselhos emergem exclusivamente das ações e das demandas espontâneas do povo e não fazem parte dele ideologias preconcebidas ou qualquer teoria sobre a melhor forma de governo" (Arendt, 1966: 499). Ou seja, Hannah Arendt apresenta, na sua análise sobre os conselhos húngaros, uma alternativa tanto ao problema da representação quanto à concepção marxiana de conselhos operários. O que ela busca com a sua concepção é desvincular a política de elementos estratégicos de disputa do poder e vinculá-la ao ato de ação coletiva. Para ela, os conselhos assumiam um papel vago no modo moderno de pensar a ação para além da facção. Esse papel significa pensar a política como uma categoria que vá além dos partidos e que gere elementos comuns de ação.

A forma como Hannah Arendt recorreu à figura dos conselhos revolucionários húngaros para pensar a reconstrução da política contemporânea foi criticada pelos mais diversos intérpretes. Canovan afirma que, para a maior parte dos intérpretes, a posição da autora sobre conselhos parece não ser realista (Canovan, 1992: 237). Benhabib considerou a sua abordagem antimoderna, especialmente na forma como ela nega a representação (Benhabib, 1996: xviii). Parece-me que é possível diferenciar duas dimensões no resgate arendtiano dos conselhos húngaros: a primeira dimensão seria a crítica à representação, que tem como objetivo resgatar a ação da dimensão da disputa do poder. Evidentemente, Hannah Arendt parece ter ido longe demais nessa tentativa, já que ela não atribui nenhum papel à representação ou à institucionalização na sua teoria dos 
conselhos. Os conselhos seriam natalidade ou o surgimento do novo contra a institucionalidade. No entanto, há uma segunda dimensão nessa abordagem que tem permanecido obscura, que é a do papel dos conselhos no interior de um possível marco institucional. Hannah Arendt abordou essa questão parcialmente, mas tocou em um elemento que faz parte da política deliberativa nos dias de hoje: a busca por elementos de ação política que não sejam estratégico-deliberativos (Cohen, 1997). Essa busca, no entanto, deve ser coadunada com elementos institucionais que dêem a esses conselhos uma permanência maior. Permitam-nos mostrar que podemos encontrar alguns desses elementos se conciliarmos a idéia de conselhos com a idéia de nova ordem secular que aparece em Da Revolução.

Em Da Revolução, o argumento sobre o novo começo é rearticulado por Hannah Arendt. Nessa obra, escrita nos anos 1960, Hannah Arendt vai falar de um novo começo 164 absoluto isento de violência e de coerção que emerge das promessas e da deliberação comum. O novo começo arendtiano em Da Revolução está espalhado no tempo e tem como paradigma histórico a revolução americana. Esta é concebida como um ato consciente de negação baseado, em primeiro lugar, na capacidade de dizer não a uma ordem política estabelecida e fundar uma outra ordem. Nesse sentido, a revolução americana começou com o não dos puritanos, que embarcaram no Mayflower, à ordem política e social inglesa. "Não foi nenhuma teoria teológica, política ou filosófica, mas sua própria decisão de deixarem para trás o velho mundo e se aventurarem em um empreendimento inteiramente seu, que deu origem a uma seqüência de atos e acontecimentos em que teriam perecido senão tivessem [...] descoberto a gramática elementar da ação política [...] cujas regras determinam o nascimento e o ocaso da ação política" (Arendt, 1971: 170). O nascimento ou novo começo é um ato pragmático originado 
da capacidade humana de dizer não a uma ordem política. Esse elemento foi partilhado pelas revoluções húngara e americana. Mas há, também, em $D a$ Revolução a ênfase em um novo elemento na revolução americana que permite uma maior institucionalização da ação. Esse elemento é a fundação de um novo corpo político estável (Arendt, 1971: 196) e sua atualização. Para Hannah Arendt, a importância do republicanismo nos Estados Unidos é que ele permitiu não apenas a instituição do novo mas também a sua permanência em uma base distinta da romana, isto é, através do constitucionalismo e de uma tradição de direitos que atualiza o ato fundacional que antecedeu a existência do próprio governo (Arendt, 1971: 200). Nesse sentido, a possibilidade de sempre voltar ao momento fundador foi, no caso dos Estados Unidos, atualizada no instituto da tradição de direitos e da revisão constitucional rompendo com a hierarquia própria à tradição romana.

Temos, assim, os dois elementos necessários para uma nova interpretação da relação entre ação e institucionalização em Hannah Arendt. De acordo com essa interpretação, a ação mantém a sua centralidade como o elemento central da política moderna. É ela, entendida como interação puramente humana, que abre espaço para novos começos e novos experimentos. Esse conceito de ação articula-se com a idéia de conselhos entendidos não como a alternativa à representação e sim como alternativa à concepção exclusivista da representação que torna os partidos a única forma de mediação política. Os conselhos cumpririam o papel fundamental no mundo moderno de propiciar uma deliberação que não esteja completamente vinculada a interesses pré-determinados. Eles cumpririam o papel de abertura nas formas de mediação entre o indivíduo e a política institucionalizada. Com isso, cria-se a possibilidade de uma forma distinta de ação passível de institucionalização e capaz de atualizar os elementos fundacionais da primeira modernida- 
de. É dessa maneira que podemos entender o legado arendtiano, trinta anos após a morte da autora, como detendo uma enorme relevância, ainda que com a necessidade de ser reinterpretado. Em um momento no qual a renovação das possibilidades políticas é mais urgente do que nunca, a obra de Hannah Arendt parece ter muito a dizer sobre como reconstituir o político na modernidade tardia.

\section{Leonardo Avritzer}

é professor do Departamento de Ciência Política da Universidade Federal de Minas Gerais - UFMG

\section{Referências bibliográficas}

ARENDT, Hannah. 1951 [1979]. The origins of totalitarianism. New York: Harcourt and Brace. . 1966. "Postface" to The origins of totalitarianism. London: Georg Allen and Unwin. 1958. The human condition. Chicago: University of Chicago Press. 1979. Entre o passado e o futuro. São Paulo: Perspectiva. 1971. Da revolução. Lisboa: Moraes Editores.

AVRITZER, Leonardo. 1996. A moralidade da democracia. São Paulo: Perspectiva.

BENHABIB, Seyla. 1996. The reluctant modernism of Hannah Arendt. Rowman and Little Field.

BOWEN-MOORE, Patricia. 1989. Hannah Arendt's philosophy of natality. New York: Saint Martin.

BRUNKHORST, Hauke. 2000. Equality and Elitism in Arendt. In: VILLA, Dana. The Cambridge Companion to Hannah Arendt. Cambridge: Cambridge University Press.

CALHOUM, Craig. 1997. Hannah Arendt and the Meaning of Politics. Minessota: University of Minessota Press.

CANOVAN, Margareth. 1992. Hannah Arendt: a re-interpretation of her political thought. Cambridge: Cambridge University Press.

COHEN, Joshua. 1997. "Deliberation and democratic legitimacy". In: REGH, William. Deliberative Democracy. Cambridge: MIT Press. 
COLLETTI, Lucio. 1985. "Introduction”. In: MARX, Karl. Early writings. New York: Vintage Press.

FINCHELY, L.; FINCHLEY, S. 1992. Hannah Arendt: Critical essays. New York: Sunny Press.

HABERMAS, Jurgen. 1968. Towards a rational society. Boston: Beacon Press. HAMMER, Dean. 2002. "Hannah Arendt and roman political thought". Political Theory, vol. 30, n-1.

HELLER, Agnes. 2000. "Hannah Arendt on Vita Contemplativa”. In: GARATH, Williams. Hannah Arendt: critical assessments. Lancaster: Lancaster University. MARX, Karl. 1975. Early writings. Edited by Lucio Colletti. New York: Vintage Press.

MATTHES, Melissa. 2000. The rape of Lucrecia and the founding of the Roman Republic. Philadelphia: Pensyvania State University Press.

SITTON, John. 1992. "Hannah Arendt's Argument for Council Democracy”. In: HINCHMAN, L.; HINCHMAN, S. (eds.). Hannah Arendt: critical essays. New York: Sunny Press.

TAMINIAUX, Jacques. 2000. "Athens and Rome”. In: VILLA, Dana. The Cambridge Companion to Hannah Arendt. Cambridge: Cambridge University Press.

VILLA, Dana. 1996. Arendt and Heidegger. Princeton: Princeton University Press.

bridge: Cambridge University Press.

YOUNG-BRUHEL, Elizabeth. 1983. Hannah Arendt: for love of the world. New Haven: Yale University Press. 


\section{AÇÃO, FUNDAÇÃO E AUTORIDADE EM HANNAH ARENDT}

\section{LEONARDO AVRITZER}

À medida que se completam 30 anos da morte de Hannah Arendt, a autora começa a se destacar como uma das principais filósofas e pensadoras sobre a natureza do político na segunda metade do século XX. Sua principal contribuição ao conceito de política é o resgate de um conceito de ação como a instauração do novo. Diversos autores já apontaram a inspiração greco-ateniense do empreendimento arendtiano. Este artigo pretende mostrar que, além da inspiração greco-ateniense que levou ao conceito da novidade da ação, a obra de Hannah Arendt também possui uma inspiração romano-republicana necessária para 
pensar a institucionalização de novas formas de ação. $O$ texto pretende mostrar que as duas dimensões estão em uma posição de tensão na obra arendtiana, e que essa tensão encontra uma solução parcial nos escritos arendtianos sobre a república nos Estados Unidos.

Palavras-chave: Hannah Arendt; Ação; Fundação; Autoridade.

\section{ACTION, FOUNDATION AND AUTHORITY IN HANNAH ARENDT}

Thirty years after Hannah Arendt's death, the author is considered one of the best political theorists of the 20th century. Hannah Arendt main contribution to political theory is her concept of action and its role in the redefinition of the political realm, in particular, the way it has inserted the idea of new beginning into modern politics. Many authors have already pointed out the Athenian inspiration of Hannah Arendt's concept of the political. In this article, it is shown that Hannah Arendt has been inspired not only by the Greek tradition but also by a Roman tradition 252 concern with the issue of institutionalization of political action. However, the text shows that both dimensions instead of being complementary stand in a tension within her oeuvre and that this tension only finds a partial solution in the Arendtian writings on the American revolution.

Keywords: Hannah Arendt; Action; Foundation; Authority. 